somes : one of them, the gene, is potentially capable of determining a particular course of cellular reactions ; the other is associated with the control of this particular action.

In the Department of Embryology the discovery that there is extensive formation of neural-crest cells by the early embryonic eye (optic vesicle) throws light on the origin of the pigmented cells which appear early in the development of the eye. The development of the earliest human kidney rudiments has been thoroughly re-investigated, and further investigation of the physiology and biochemistry of uterine muscle has demonstrated that the 'staircase phenomenon', long known in heart muscle, occurs also in uterine muscle, and that the slope of the staircase is reversed by treatment with the corpus luteum hormone, progesterone. The discovery points to an essential role of potassium ions in uterine muscle contraction, and suggests that progesterone can modify the movement of potassium in and out of the muscle cell.

\section{OPTICAL SOCIETY OF AMERICA}

\section{ANNUAL MEETING IN BOSTON}

$\mathrm{T}$ HE thirty-seventh annual meeting of the Optical Society of America was held during October 9-11, 1952, at Boston, Mass. Twenty-two invited papers covering spectroscopy, computational aids and atmospheric effects, in addition to other fields of science bordering on optics, were presented. The titles and abstracts of these papers and of the other contributed papers, together with a brief report of the proceedings of the meeting, are printed in the Novomber issue of the Society's Journal (42, $868 ; 1952$ ).

The invited papers include a discussion by $N$. Wiener on optics and the nature of spectra, a review of hyperfine structure investigations by F. Bitter, and a description of germanium phototransistors by J. N. Shive, of the Bell Telephone Laboratories. Various aspects of spectroscopy and radio astronomy are covered by communications from G. H. Harrison, R. Tousey, E. M. Purcoll and others, including, in particular, one on multi-channel spectrometry by F. B. Follgett, of the University Observatories, Cambridge. In addition, a review of recent developments in infra-red spectroscopy is given by R. C. Lord.

Three papers are devoted to the subject of "Flying Saucers"'. It is pointed out by D. H. Menzel, of the Harvard College Observatory, that about one-fifth of the numerous reports received by the United States Air Forces did not admit of a simple explanation but that the majority of these, when examined carefully, could be explained as due to atmospheric physical phenomena, such as mirages, or reflexions from layers of fog or haze, or from ice-crystals. From a study of several hundred reports of unidentified aerial objects, it is concluded by A. Hynek, of the Ohio State University, that only one phenomenon, that of a hovering nocturnal light, is not readily explicable on an astronomical basis, and, finally, it is definitely stated by U. Liddel, of the Bendix Aviation Corporation, that no evidence exists for any phenomena not explicable by standard physical concepts.

The annual business meeting of the Society was held on the morning of October 10, and the annual banquet, preceded by a cocktail party given by the
American Optical Company, during the evening. At the banquet, over which the Society's president, Brian O'Brien, presided, the Adolph Lomb Medal was presented to Dr. A. B. Meinel, of the Yerkes Observatory, and the Frederic Ives Medal to Dr. Ira $\mathrm{S}$. Bowen, director of the Mount Wilson and Palomar Observatories. The after-dinner speaker was Dr. Harlow Shapley, of the Harvard College Observatory, who spoke on the subject of galaxies. The Adolph Lomb Medal is awarded to $\mathbf{a}$ promising scientist under thirty years of age, and the Frederic Ives Medal, which was established in 1928 by Herbert Ives in honour of his father, is for distinguished work in optics. Both medals are awarded every two years.

On receiving his medal, Dr. Bowen gave an address, entitled "Optical Problems at the Palomar Observatory", in which he described the support systems and the testing of the mirror and methods of increasing the effectiveness of the 200-in. Hale telescope, the main instrument at the Observatory. The mirror is a paraboloid of $660 \mathrm{in}$. focus ; but, in addition, convex hyperboloids are provided which, when combined with the main mirror, give telephoto systems of which the focal lengths are $3,200 \mathrm{in}$. at the Cassegrain focus and 6,000 in. at the coudé focus. In addition to the mirror, the equipment of the Observatory includes three Schmidt cameras of 8, 18 and $48 \mathrm{in}$. apertures and operating at focal ratios of 1,2 and $2 \cdot 5$, respectively. Dr. Bowen remarked that the cameras have remarkably fine definition over fields $9-20^{\circ}$ in diameter and are efficient instruments for the rapid photography of large areas of the sky. Nearly all the equipment deseribed has been in operation for from six months to three years, and the performance has come well up to expectation.

\section{BRITISH ASSOCIATION OF CHEMISTS HINCHLEY HOUSE}

$T$ HE British Association of Chemists has recently acquired a freehold property, 14 Harley Street, London, W.1, for use as its headquarters. It was decided to name the premises 'Hinchley House' in memory of Prof. J. W. Hinchley, a founder member and the first president (1918-23). It was due to his influence and skill in directing its policy that the Association survived its first four difficult years. Prof. Hinchley was also instrumental in founding the Institution of Chemical Engineers, and his name will always be associated with chemical engineering, for many of the advances it has made in Great Britain are due to his conviction of its importance to industry and the necessity of making it a specialized branch of scientific study. The name of Prof. Hinchley had earlier been perpetuated through the annual award of the Association's Hinchley Medal, which is given for outstanding services to the profession of chemistry.

An opening ceremony was held at the new headquarters on February 27 , when a number of members and guests, representing other bodies connected with the profession of chemistry, were present. Mr. F. Scholefield, president of the Association, in declaring the premises open, said that this function was indeed a red-letter day in the history of the British Association of Chemists, which thus became the first society of chemists to possess its own freehold property in London. The Association was formed in 1917 owing 